\title{
A inclusão do aluno surdo na rede regular de ensino
}

\section{The inclusion of deaf students in regular education}

\author{
Fernanda Arndt Mesenburg da Silva* \\ Rosana Aparecida Treml**
}

Resumo: A surdez tem uma longa história iniciada na Antiguidade, quando surdos eram vistos com piedade e até sacrificados. Na Idade Média, a surdez passou a ser vista como anomalia sobrenatural. Com o transcorrer dos séculos, pouco ou nada mudou para os surdos com sua inserção na sociedade. No final da década de 70, surgiu um método que combinava língua de sinais, oralidade, leitura labial, treino auditivo e o alfabeto manual, chamado Abordagem Total. No Brasil, a surdez foi preocupação inicialmente no Rio de Janeiro, época do II Reinado. Passados 152 anos de descaso, mudanças foram sentidas. Com a LDB 9394/96 (Artigo 59), o Plano Nacional de Educação no início do século XX, através da Lei 10.172/2001 e a lei Federal n 10.436/2002, a Língua Brasileira de Sinais foi reconhecida como meio legal de comunicação e expressão do surdo. Tendo como acréscimo mais recente o Decreto n ${ }^{\circ} 6.094 / 2007$, que traz a permanência de todos no ensino regular e o atendimento adequado às necessidades especiais, é notória a lentidão e as barreiras enfrentadas pelos surdos quanto à participação social dominada por ouvintes. Não bastam legislação e propostas de inclusão para que o surdo seja realmente incluído enquanto cidadão do mundo, é necessário reformular conceitos, valores, atitudes, estruturas familiares e educacionais. A surdez é a mais complexa das necessidades especiais, porque é invisível aos olhos humanos, mas o fato de não ouvir não os torna incapazes. Para concretizar a pesquisa, partiu-se de um estudo de caso, de um aluno surdo que cursou, até 2007, Escola Especial e em 2008 foi incluído no ensino regular público, com apoio de intérprete somente a partir do segundo semestre. Buscou-se perceber os obstáculos por ele enfrentados nessa trajetória de inclusão. O salto monumental realizado pelo aluno foi desesperador, saiu de uma proposta pedagógica imagética para uma proposta pedagógica teórico-abstrata, provocando angústia profunda nos profissionais da educação e também no surdo. Tenho um aluno surdo, e agora?

Palavras-chave: Inclusão. Surdez. Escola especial. Ensino regular.

Abstract: The deafness has a long history began in antiquity, in which the deaf were viewed with pity and even killed.In the Middle Ages, deafness is now seen as supernatural anomalies. The centuries passed and little or nothing has changed for the deaf in their integration into society. At the end of the '70s emerged a method that combined language of signs, verbal, auditory training and

\footnotetext{
Graduanda do Curso de Licenciatura em Pedagogia na Universidade Estadual de Ponta Grossa. E-mail: fernandamesenburg@yahoo.com.br

Graduação em Licenciatura em História pela Universidade Estadual de Ponta Grossa e Especialista em educação Especial pelo ESAP - Instituto de Estudos Avançados e Pós-Graduação - Faculdade Iguaçu. E-mail: rosanatreml@pop.com.br
} 
the manual alphabet, called the Total Approach. In Brazil, the deafness was initial concerned in the Reign II in Rio de Janeiro. After 157 years of neglect, recent law, like the Law 9394/96, Article 59, and the National Plan for Education, in the early twentieth century, Law 10.1725/2001 and reaches its apex with the Law 10.463/2002 that recognized the Brazilian Sign Language as a legal means of communication and expression of the deaf. With the most recent addition to Decree 6.094/2007, that brings the permanence of all in regular teaching and provides appropriate service to the special needs. It is known the slow and the barriers faced by deaf people as social participation dominated by listeners. It is not enough legislation and inclusion proposals for the deaf to be actually included as citizens of the world. It is necessary to review concepts, values, attitudes, family and educational structures. The deafness is more complex of all special needs, because it's invisible to human eyes, but the fact of not hearing does not make a person disabled. To complete the research, we started with a case study of a deaf student who studied in a special school until 2007 and in 2008 he was included in regular education, with support of an interpreter only from the second semester on. We tried to understand the obstacles faced by him in his way for inclusion. The monumental leap achieved by the student was trying. He left a teaching proposal which worked just with images for a theoretical and abstract pedagogical proposal, causing deep anxiety in professional educators and also the deaf. I have a deaf student, and now?

Keywords: Inclusion. Deafness. Special school. Regular teaching.

\section{Introdução}

A educação inclusiva é muito ampla e de alta complexidade, mesmo no mundo moderno e tecnológico tal como se apresenta atualmente, por isso ela deve ser amplamente estudada e discutida. Devemos lançar para ela um olhar especial, sem preconceito nem demagogia, mas na medida certa, devemos analisá-la.

Não basta a modernidade, nem o discurso da diversidade, se não houver propostas consistentes de uma inclusão realmente eficaz. O mito, a descrença e o apego às tradições equivocadas, muitas vezes impostas por um modelo de sociedade que se envergonha do diferente, continuam a pressionar a favor de uma permanência da exclusão ao invés de repensar, resignificar conceitos e atos partindo para uma concretização do novo paradigma: a inclusão social.

É sabido que a inclusão não acontece por imposição de leis ou decretos, mas tem seu aporte centralizado na sociedade democrática, humana.

Com o intuito de desmitificar a surdez, direciona-se o estudo para demonstrar que a barreira da comunicação permanece muito forte na escolarização formal, acadêmica, inclusiva no ensino regular, reforçando que o lugar do deficiente é na escola especial. Assim, o presente ensaio tem como objetivo central, após a verificação dos processos de inclusão do aluno surdo na rede 
regular de ensino, apontar os obstáculos que ainda impedem a concretização de uma educação inclusiva.

Tendo esse foco determinado, o desenvolvimento do nosso raciocínio pautou-se na metodologia de estudo de caso, com pesquisa de campo realizada na rede pública de ensino, questionário aberto e depoimentos, acrescidos de pesquisa bibliográfica. Além dessas estratégias, realizou-se uma comparação entre os materiais produzidos na escola especial no ano de 2007 e na quinta série do ensino regular em 2008.

\section{Breve relato histórico da legislação da educação especial no Brasil}

A discussão mundial pela inclusão tem caráter político, cultural, social e pedagógico, tendo como foco a aprendizagem e participação conjunta, sem preconceito, sem nenhum tipo de discriminação, colocando a educação como um direito de todos.

A busca pela educação inclusiva tornou-se uma luta embasada na concepção de direitos humanos, que prioriza o fim da exclusão dentro e fora da escola.

A prática da educação inclusiva surgiu como necessidade de delimitar o fim das diferenças, oferecendo meios para superá-las, assumindo papel central no debate contra a exclusão.

A partir do despertar da consciência da exclusão educacional, houve necessidade de repensar a prática pedagógica, como por exemplo, a organização de escolas e das classes especiais, mudando o paradigma de escolas normais e de escolas especiais, para uma escola em que todos os alunos tenham suas especificidades atendidas.

Nessa perspectiva, o Ministério da Educação/Secretaria de Educação Especial apresenta a Política Nacional de Educação Especial na Perspectiva da Educação Inclusiva, acompanha os avanços do conhecimento e das lutas sociais, visando constituir políticas públicas promotoras de uma educação de qualidade para todos os alunos.

No Brasil, o atendimento específico às pessoas surdas teve início na época do Império com a criação o Instituto dos Surdos Mudos, em 1857, atual Instituto Nacional da Educação dos Surdos - INES, ambos no Rio de Janeiro. 
Em 1961, o atendimento educacional às pessoas com deficiência passa ser fundamentado pelas disposições da Lei de Diretrizes e Bases da Educação Nacional, Lei nº . 4.024/61, que aponta o direito dos “excepcionais" à educação, preferencialmente dentro do sistema geral de ensino.

A Lei no. 5.692/71 que altera a LDBEN de 1961 ao definir "tratamento especial” para os alunos com "[...] deficiências físicas, mentais, os que se encontrem em atraso considerável quanto à idade regular de matrícula e os superdotados”, não promove a organização de um sistema de ensino capaz de atender às necessidades educacionais especiais e acaba reforçando o encaminhamento dos alunos para as classes e escolas especiais.

A Constituição Federal de 1988 (Art. $3^{\circ}$ inciso IV) traz como um dos seus objetivos fundamentais, "[...] promover o bem de todos, sem preconceitos de origem, raça, sexo, cor, idade e quaisquer outras formas de discriminação”. Ela define, no artigo 205, a educação como um direito de todos, garantindo o pleno desenvolvimento da pessoa, o exercício da cidadania e a qualificação para o trabalho. No seu Artigo 206, inciso I, estabelece a "[...] igualdade de condições de acesso e permanência na escola”, como um dos princípios para o ensino e, aponta como dever do Estado, a oferta do atendimento educacional especializado, preferencialmente na rede regular de ensino. (Constituição..., 1988, Art. 208).

O Estatuto da Criança e do Adolescente - Lei no ${ }^{\circ}$ 8.069/90, Artigo 55 , reforça os dispositivos legais supracitados, ao determinar que "[...] os pais ou responsáveis têm a obrigação de matricular seus filhos ou pupilos na rede regular de ensino".

Constam também, desta década, documentos como a Declaração Mundial de Educação para Todos (1990) e a Declaração de Salamanca (1994), que passam a influenciar a formulação das políticas públicas da educação inclusiva.

Em 1994 é publicada a Política Nacional de Educação Especial, orientando o processo de "integração instrucional" que condiciona o acesso às classes comuns do ensino regular àqueles que "[...] possuem condições de acompanhar e desenvolver as atividades curriculares programadas do ensino comum, no mesmo ritmo que os alunos ditos normais". (POLITICA NACIONAL DE EDUCAÇÃO ESPECIAL, 1994, p.19). 
A atual Lei de Diretrizes e Bases da Educação Nacional - Lei ${ }^{\circ}$. 9.394/96, no Artigo 59, preconiza que os sistemas de ensino devem assegurar aos alunos currículo, métodos, recursos e organização específicos para atender às suas necessidades; assegura a terminalidade específica àqueles que não atingiram o nível exigido para a conclusão do ensino fundamental, em virtude de suas deficiências e a aceleração de estudos aos superdotados para conclusão do programa escolar. Também define, dentre as normas para a organização da educação básica, a "[...] possibilidade de avanço nos cursos e nas séries mediante verificação do aprendizado” (LDBEN, 1996, Art. 24, inciso V) e "[...] oportunidades educacionais apropriadas, consideradas as características do alunado, seus interesses, condições de vida e de trabalho, mediante cursos e exames”. (LDBEN, 1996, Art. 37).

Em 1999, o Decreto $n^{\circ} .3 .298$ que regulamenta a Lei $n^{0}$. 7.853/89, ao dispor sobre a Política Nacional para a Integração da Pessoa Portadora de Deficiência, define a educação especial como uma modalidade transversal a todos os níveis e modalidades de ensino, enfatizando a atuação complementar da educação especial ao ensino regular.

Acompanhando o processo de mudanças, as Diretrizes Nacionais para a Educação Especial na Educação Básica, Resolução CNE/CEB nº. 2/2001, no artigo $2^{\circ}$, determinam que:

Os sistemas de ensino devem matricular todos os alunos, cabendo às escolas organizar-se para o atendimento aos educandos com necessidades educacionais especiais, assegurando as condições necessárias para uma educação de qualidade para todos. (MEC/SEESP, 2001).

O Plano Nacional de Educação - PNE, destaca que "[...] o grande avanço que a década da educação deveria produzir seria a construção de uma escola inclusiva que garanta o atendimento à diversidade humana”. (2001, p. 86). Ao estabelecer objetivos e metas para que os sistemas de ensino favoreçam o atendimento às necessidades educacionais especiais dos alunos, a lei indica uma deficiência no que diz respeito à oferta de matrículas para alunos com dificuldades específicas nas classes comuns do ensino regular, à formação docente, à acessibilidade física e ao atendimento educacional especializado.

A Convenção da Guatemala (1999), promulgada no Brasil pelo Decreto ${ }^{0}$ 3.956/2001, afirma que as pessoas com deficiência têm os mesmos direitos humanos e liberdades fundamentais que as demais, definindo como 
discriminação com base na deficiência, toda diferenciação ou exclusão que possa impedir ou anular o exercício dos direitos humanos e de suas liberdades fundamentais. Esse Decreto tem importante repercussão na educação, exigindo uma reinterpretação da educação especial, compreendida no contexto da diferenciação adotada para promover a eliminação das barreiras que impedem o acesso à escolarização.

A Lei $n^{0}$ 10.436/02 reconhece a Língua Brasileira de Sinais como meio legal de comunicação e expressão, determinando que sejam garantidas formas institucionalizadas de apoiar seu uso e difusão, bem como a inclusão da disciplina de Libras como parte integrante do currículo nos cursos de formação de professores e de fonoaudiologia.

Em 2003, o Ministério da Educação cria o Programa Educação Inclusiva: direito à diversidade, visando transformar os sistemas de ensino em sistemas educacionais inclusivos, que promove um amplo processo de formação de gestores e educadores nos municípios brasileiros para a garantia do direito de acesso de todos à escolarização, a organização do atendimento educacional especializado e à promoção da acessibilidade.

Em 2004, o Ministério Público Federal divulga o documento "O Acesso de Alunos com Deficiência às Escolas e Classes Comuns da Rede Regular", com o objetivo de disseminar os conceitos e diretrizes mundiais para a inclusão, reafirmando o direito e os benefícios da escolarização de alunos com e sem deficiência nas turmas comuns do ensino regular.

O Decreto $n^{0} 5.626 / 05$, que regulamenta a Lei $n^{\circ}$. 10.436/2002, visando à inclusão dos alunos surdos, dispõe sobre a inclusão da Libras como disciplina curricular, a formação e a certificação de professor, instrutor e tradutor/ intérprete de Libras, o ensino da Língua Portuguesa como segunda língua para alunos surdos e a organização da educação bilíngue no ensino regular.

A Convenção sobre os Direitos das Pessoas com Deficiência, aprovada pela ONU em 2006, da qual o Brasil é signatário, estabelece que os Estados devem assegurar um sistema de educação inclusiva em todos os níveis de ensino, em ambientes que maximizem o desenvolvimento acadêmico e social compatível com a meta de inclusão plena, adotando medidas para garantir que:

a) As pessoas com deficiência não sejam excluídas do sistema educacional geral sob alegação de deficiência e que as crianças com deficiência 
não sejam excluídas do ensino fundamental gratuito e compulsório, sob alegação de deficiência;

b) As pessoas com deficiência possam ter acesso ao ensino fundamental inclusivo, de qualidade e gratuito, em igualdade de condições com as demais pessoas na comunidade em que vivem. (CONVENÇÃO SOBRE OS DIREITOS DA PESSOA COM DEFICIÊNCIA, 2006, Art. 24).

Em 2006, a Secretaria Especial dos Direitos Humanos, o Ministério da Educação, o Ministério da Justiça e a UNESCO lançam o Plano Nacional de Educação em Direitos Humanos que objetiva, dentre as suas ações, fomentar, no currículo da educação básica, as temáticas relativas às pessoas com deficiência bem como desenvolver ações afirmativas que possibilitem inclusão, acesso e permanência na educação superior.

Em 2007, no contexto com o Plano de Aceleração do Crescimento PAC, é lançado o Plano de Desenvolvimento da Educação - PDE, reafirmado pela Agenda Social de Inclusão das Pessoas com Deficiência, tendo como eixos a acessibilidade arquitetônica dos prédios escolares, a implantação de salas de recursos e a formação docente para o atendimento educacional especializado.

No documento "Plano de Desenvolvimento da Educação: razões, princípios e programas”, publicado pelo Ministério da Educação, é reafirmada a visão sistêmica da educação que busca superar a oposição entre educação regular e educação especial.

Contrariando a concepção sistêmica da transversalidade da educação especial nos diferentes níveis, etapas e modalidades de ensino, a educação não se estruturou na perspectiva da inclusão e do atendimento às necessidades educacionais especiais, limitando, o cumprimento do princípio constitucional que prevê a igualdade de condições para o acesso e permanência na escola e a continuidade nos níveis mais elevados de ensino. (PLANO NACIONAL DE EDUCAÇÃO, 2007, p. 09).

O Decreto $n^{\circ}$ 6.094/2007 estabelece dentre as diretrizes do Compromisso Todos pela Educação, a garantia do acesso e da permanência no ensino regular e o atendimento às necessidades educacionais especiais dos alunos, fortalecendo a inclusão educacional nas escolas públicas. 
3 Histórico da educação dos surdos

No decorrer da história da humanidade, a ideia que se fazia a respeito dos surdos era sempre muito negativa, uma vez que as pessoas não possuíam esclarecimentos a respeito do tema, e, muitas vezes, olhavam o "diferente" com preconceito e impotência, diante de uma situação da qual não tinham conhecimento específico.

Na Antiguidade, os surdos foram vistos de diferentes formas: castigo dos deuses, piedade, enfeitiçados, sacrificados. Na Bíblia, pode-se perceber uma posição negativa da surdez, "[...] no princípio era o Verbo, e o Verbo estava com Deus, e o Verbo era Deus”. (SACKS, 1989). Entende-se que, se os desígnios de Deus eram expressos através das palavras, o surdo, em sua limitada condição, não se fazia merecedor dessa inclusão. Viviam à margem da sociedade sem nenhum direito assegurado.

Para Márcia Goldfeld (1997), na obra "A criança surda”, a partir do século XVI tem-se notícias dos primeiros educadores surdos. Há posições contraditórias quanto a essa informação, pois no artigo de Zuleide Rodrigues publicado em 10 de janeiro de 2008, se destaca que até o início da Idade Moderna não se havia notícias de experiências educacionais com as crianças surdas. O surdo era visto como um ser irracional, primitivo, não educável, não cidadão; pessoas castigadas e enfeitiçadas, como doentes privados de alfabetização e instrução, forçados a fazer os trabalhos mais desprezíveis; viviam sozinhos e abandonados na miséria. Eram considerados pela lei e pela sociedade como imbecis. Não tinha nenhum direito e também eram sacrificados. A história dos surdos começou assim: triste, muda e dolorosa. A ideia que se tinha sobre os surdos era de piedade e tamanha ignorância.

Segundo Goldfeld (1997), alguns educadores, assim como atualmente, criaram diferentes metodologias para ensinar o surdo. Alguns se basearam na linguagem oral, ou seja, a língua auditiva-oral utilizada em seu país, como o francês, inglês entre outras línguas; outros defenderam a língua de sinais, que é uma língua espaço-visual-espacial, criada através de gerações pela comunidade de surdos.

Ainda no século XVI, na Espanha, o monge beneditino Pedro Ponce de Leon (1520-1584) criou uma metodologia que incluía datilologia (representação manual das letras do alfabeto) escrita e oralizada e ensinou quatro surdos. Criou também uma escola de professores surdos. (KOJIMA, 2008). 
Ao longo dos anos podemos visualizar algum esforço da sociedade para facilitar a vida dos surdos, numa tentativa de inclusão. Em 1644, foi publicado o primeiro livro em inglês sobre a língua de sinais Chirologia, de J. Bulwer, que acreditava ser a língua de sinais universal. Em 1712-1789 surgiu na França o Abade Michel de L’Epée a primeira escola para crianças surdas, onde foi utilizada a língua de sinais, uma combinação dos sinais com a gramática francesa, com o objetivo de ensinar a ler, escrever, transmitir a cultura e dar acesso à educação. O método de L’Epée teve sucesso e obteve os resultados espetaculares na história da surdez. Em 1791, a sua escola se transforma no Instituto Nacional de Surdos e Mudos de Paris, e foi dirigido por seu seguidor, o gramático Sicard. Na Alemanha, em 1750, com as ideias de Samuel Heinick, surgiram as primeiras noções da educação Oralista: acreditava-se na língua oral e não na língua de sinais; funda-se a primeira escola pública baseada no método oral para surdos e tinha apenas nove alunos. As metodologias desses autores se confrontam. (KOJIMA, 2008).

No século XIX, os Estados Unidos se destacam na educação de surdos utilizando a ASL (Língua de Sinais Americana), tendo a influência da língua de sinais francesa trazida por Laurent Cler, um professor surdo francês, discípulo do Abad Sicard, seguidor de L’Epée, fundando junto com Thomas Gallaudet, a primeira escola americana para surdos e, em 1864, sendo a única Universidade para surdos no mundo. A partir de 1880 e até a década de 70 desse mesmo século, em todo o mundo a educação dos surdos foi seguindo e se conformando com a orientação oralista decidida no Congresso de Milão, tendo como maior defensor e que exerceu grande influência no resultado Alexander Graham Bell, o Oralismo venceu, e a língua de sinais foi oficialmente proibida. (KOJIMA, 2008).

É nesse momento que se insere no Brasil a educação de surdos, com a criação do Instituto de Surdos-Mudos, hoje o atual Instituto Nacional de Educação de Surdos (INES). Fundado em 26 de setembro de 1857, pelo professor surdo francês Ernet Hwet, que veio ao Brasil a convite do Imperador D. Pedro II para trabalhar na educação de surdos que, no início, eram educados por linguagem escrita, articulada e falada, datilogia e sinais. A disciplina "Leitura sobre os Lábios" estaria voltada apenas para os que apresentassem aptidões a desenvolver a linguagem oral. Assim se deu o primeiro contato com a Língua de Sinais Francesa trazida por Hwet e a língua dos sinais utilizada pelos alunos. É importante ressaltar que naquele tempo o trabalho de oralização era feito pelos professores comuns, não havendo especialistas. Em 
1911, o INES, seguindo a tendência mundial, implantou o Oralismo puro, a língua de sinais sobreviveu até 1957, quando foi proibida em sala de aula. Na década de 70, Doroty Schifflet, professora e mãe de surdo, começou a utilizar um método que combinava a língua de sinais, a língua oral, a leitura labial, o treino auditivo e o alfabeto manual, denominando seu trabalho (já traduzido) de Abordagem Total. Em 1968, teve início a Comunicação Total, que considera todas as formas de comunicação possíveis na educação dos surdos, inclusive no Brasil. A partir de 1980, surgiu a filosofia bilíngue em todo o mundo e, em 1990, ganhou inúmeros adeptos. (KOJIMA, 2008).

A história da educação de surdos no Brasil e no mundo vem confirmar a necessidade de repensar a prática pedagógica dos alunos surdos, percebe-se que a inclusão é necessária e que a partilha de experiências, informações e conhecimentos, só possuem valor se forem repassados. Na maioria dos casos, a integração do aluno surdo requer a presença de um professor que colabore dentro da sala de aula de modo que favoreça o progresso e a aprendizagem, seja acompanhado de uma intérprete, ou seja, de uma pessoa capacitada na língua de sinais e na Comunicação Total.

No Brasil, as Secretarias Estaduais e Municipais de Educação passaram a coordenar o ensino das crianças com necessidades especiais (inicialmente denominadas portadoras de deficiências) e surgiram as Salas de Recursos e Classes Especiais para surdos, além de algumas Escolas Especiais, com recursos públicos ou privados. Com a organização das minorias no âmbito mundial, por terem garantido seus direitos de cidadãos, as pessoas portadoras de necessidades especiais passaram a apresentar suas reivindicações que, no caso dos surdos, são: o respeito à língua de sinais, um ensino de qualidade, acesso aos meios de comunicação (legendas, serviços de intérpretes), entre outras. De acordo com a Lei 10.436/02, Libras é uma Língua, própria da comunidade surda.

\section{Surdez e sociedade}

O histórico anteriormente mencionado nos aponta a trajetória percorrida pelos surdos na sociedade que, vistos como incapazes, eram excluídos do meio de convívio social. 
Com base nesses aspectos, pretende-se discutir as barreiras sociais enfrentadas pelo surdo no seu processo de inserção social.

O termo inclusão, constantemente discutido, nos remete a reflexões muito amplas. Em termos legais verificou-se que o Brasil apresenta sua legislação específica, com o intuito de concretizar o processo de inclusão em todas as esferas da sociedade. Porém, sabe-se que não só a legislação precisa ser cumprida, como também existe a necessidade de reformulação dos conceitos presentes na sociedade.

Para que o processo de inclusão de fato ocorra, mudanças que visem à alteração de valores e atitudes, assim como modificações na estrutura da sociedade, são necessárias. Verificar, perceber e respeitar as diferenças individuais são valores morais muito importantes.

A família também é de fundamental importância nos processos de inclusão. Ainda cabe a ela o preparo de seus membros para a vida e para o respeito às regras existentes em nossa sociedade. Ela, tanto quanto a escola tem sua importância no processo de concretização de uma sociedade inclusiva.

Os esforços para que se possa concretizar essa sociedade inclusiva, devem ser constantes. Como exemplo disso, toma-se como ponto de referência a seguinte frase de Marcelo Faccini - Intérprete de Libras.

Transformar a desilusão em vigor renovado, o desapontamento em coragem, o desespero em esperança e descobrir que o que pareciam ‘ obstáculos ‘intransponíveis' eram simples ‘degraus'. È o desafio da própria vida [...] (LIBRAS Língua Brasileira de Sinais - Imagem do pensamento. 2008, V. 3, p. 2).

A sociedade inclusiva é composta por diferentes deficiências, em especial a surdez, considerada uma limitação quase que invisível aos olhos humanos, porém a realidade se mostra distinta. Para tanto a frase de Catarina Kiguti Kojima - arte educadora e pedagoga especializada em educação de surdos - elucida claramente o foco de estudo, que diz:

Respeitar o surdo como cidadão é, antes de mais nada, querer que esse cidadão faça parte da nação, seja um individuo atuante capaz de exercer a sua profissão. (LIBRAS Linguagem Brasileira de Sinais - Imagem do Pensamento, 2008, v.1, p.2). 
O fato de não ouvir não os torna seres incapazes ou com baixo nível intelectual, ao contrário, os surdos são dotados das mesmas condições que o individuo ouvinte, no entanto com a limitação auditiva que faz com que eles encontrem outros meios de viver e conviver em sociedade.

A maior dificuldade enfrentada pelos surdos é a comunicação. Para facilitar esse processo, eles se utilizam da Língua Brasileira de Sinais (Libras), que é considerada uma língua própria da comunidade surda. A produção da linguagem é feita através de signos gestuais e espaciais e sua percepção é por meio de processos visuais. Para o entendimento do processo de leitura, por exemplo, os ouvintes fazem uso da audição para decifrar os sons que cada letra emite ao ser pronunciada. No caso dos surdos essa audição é inexistente. Eles superam essa limitação através dos demais sentidos aguçados, possibilitando assim a comunicação gestual, ou seja, a Libras. A Língua é composta por sinais que, ao serem interpretados, concretizam a comunicação. Reafirma-se que esses sinais são elaborados exclusivamente pelos surdos, não cabendo a um ouvinte interferir nesse processo. Sabe-se que:

[...] as Línguas de sinais são sistemas de comunicação desenvolvidos pelas comunidades surdas, constituindo-se em línguas completas com estruturas independentes das línguas orais. (LIBRAS Linguagem Brasileira de Sinais - Imagem do Pensamento. 2008, v. 1, p. 4).

Portanto, apresenta um conjunto próprio de regras gramaticais, o que desbanca o mito de que a comunicação dos surdos não passa de meros sinais previamente estabelecidos, pois a leitura de mundo não se corporifica ou depende única e exclusivamente da linguagem oral.

Paulo Freire nos dizia que para realizar a leitura da palavra antes era preciso "ler" o mundo ao qual pertencemos e interagimos. Para os surdos, essa leitura de mundo e do seu meio de interação social depende de sua comunicação, de sua forma de interagir, de sua maneira de expressão.

A linguagem de sinais os auxilia nesse processo à medida que os torna seres capazes, atuantes e com pleno domínio de entendimento das questões sociais. Devido à clareza premente da comunicação e de uma linguagem corporificada, codificada, foi criada a Libras, língua materna do surdo. É a comunicação com a qual estabelece o primeiro contato a partir do nascimento. Parte-se desse princípio para se falar sobre identidade surda. 
O indivíduo com surdez cria sua identidade na medida em que se aceita como surdo, como indivíduo privado do sentido da audição e que necessita, dentro de suas limitações, viver e se desenvolver na sociedade. Com essa identidade formada, ele assimila suas características individuais, seu modo de ser e agir enquanto deficiente auditivo.

A identidade está constantemente sendo criada e reformulada, sofre interferência do meio em que o individuo se encontra, das pessoas com as quais convive. Essa identidade surda está fortemente ligada à cultura surda. Ao falar de cultura, automaticamente acredita-se que essa tem origem em um determinado grupo com características únicas, singulares. Cultura expressa as diferenças existentes entre os membros de uma sociedade.

Dentro de uma dimensão maior, os surdos formam um outro grupo que também apresentam suas características específicas como língua, valores e crenças. Ainda excluídos da plena convivência social, eles percebem essa necessidade de identificação e estabelecimento de um modo de vida específico.

Participam, simultaneamente, de duas organizações sociais: as de ouvintes - maior e que exige uma adequação dos mesmos aos seus costumes desconsiderando suas diferenças e limitações, e as de não ouvintes, onde podem assumir suas particularidades originadas em decorrência de uma limitação física que, ao contrário do que julga a maioria da população, não os torna incapazes de exercer sua função social.

Por esse motivo, quando mencionado o termo cultura surda, ele se refere aos movimentos por eles produzidos, que auxiliam na formação de sua identidade enquanto surdo.

\section{Estudo de caso}

Partindo da análise dos aspectos que envolvem a surdez discutidos anteriormente, chega-se ao foco do ensaio: a inclusão de fato de um aluno surdo na rede regular de ensino.

Sabemos quais os requisitos necessários para que tal inclusão ocorra. No entanto, evidenciamos também que, na prática, esse processo não funciona de forma satisfatória. O aluno, ao qual iremos nos referir como Aluno A, apresenta em sua trajetória escolar passagem por escolas especiais e também 
de ensino regular. A deficiência auditiva do Aluno A foi detectada por volta de 1 ano de idade. O procedimento inicial adotado pela mãe foi levá-lo a um Otorrinolaringologista. Com um 1 ano e 9 meses, começou a receber atendimento especializado na escola especial Geny de Jesus Ribas. Nesse período a mãe iniciou a aprendizagem da Libras. Aos 3 anos passou para o processo de escolarização que durou até os 11 anos. Sua inserção na rede regular foi no ano de 2008 quando começou a cursar a $5^{a}$ série do Ensino Fundamental. O Aluno A frequentava, simultaneamente, duas escolas - a regular e a especial, que realizava o apoio escolar para que o aluno acompanhasse melhor o desenvolvimento das aulas. O que deve ser frisado é que, na rede regular de ensino, o Aluno A passou a contar com o auxílio de uma intérprete apenas no $2^{\circ}$ semestre do ano letivo.

Para melhor expor o caso do aluno em questão, apresentamos a seguir o depoimento da mãe e de alguns de seus professores, abordando o desempenho do aluno e as questões referentes ao processo de inclusão.

Relato da mãe:

a) Como foi a aprendizagem do seu filho?

- Foi boa.

b) Quantos professores trabalharam com o seu filho por ano?

- Oito professoras.

c) Quem da família domina a Libras?

— Somente a mãe.

d) Como foi a inserção do seu filho no Ensino Regular - 5a série?

- Foi boa. No início um pouco de dificuldades, sem intérprete. Depois, no segundo semestre veio a intérprete e tudo ficou mais fácil. Ela cobrava a realização das atividades, interpretava os conteúdos, auxiliava na verificação das anotações de datas de provas e trabalhos.

e) Como foi o relacionamento com os colegas de classe?

- Bem tranquilo, conhece todo mundo, brinca com todos, nunca foi discriminado, ao contrário, estavam sempre atentos para colaborar mesmo sem saber Libras se resolviam entre eles, retirando dúvidas, informando o que o professor queria saber logo no início. 
A inclusão do aluno surdo na rede regular de ensino

f) Quais as disciplinas que sentiu dificuldade?

— Língua Portuguesa.

g) Quais as disciplinas que sentiu facilidade?

- Geografia.

h) Houve real aprendizagem na sua concepção e comparação entre a Escola Especial e o Ensino Regular?

- Houve aprendizagem sim, mesmo na escola especial fazendo mais colagem, isso não quer dizer que não aprendeu, pois a prova está no progresso e aprovação por mérito da $5^{\mathrm{a}}$ para $6^{\mathrm{a}}$ série. Trouxe pré-requisitos da escola especial bem consolidados. A diferença é que na escola especial as professoras não incentivam os alunos a falar, elas preferem Libras, sendo que meu filho muitas vezes não precisa de Libras, pois faz também leitura labial.

\section{Declaração do Professor de Educação Física:}

O Aluno A tem facilidade nas aulas de Educação Física, pois as atividades a serem desenvolvidas normalmente são demonstradas. Assim não tenho dificuldades de comunicação com o educando. O mesmo apresenta uma vantagem natural, é espontâneo, extrovertido e muito bem integrado à turma, facilita a interação professor-aluno-turma. Quando preciso de uma comunicação mais efetiva ou direta, tenho um aluno que me auxilia. Na ausência desse aluno, a comunicação e o entendimento ficam extremamente comprometidos. Tenho certeza de que é fundamental ao professor o conhecimento básico da língua de sinais. (informação verbal).

\section{Declaração do Professor de Matemática:}

No início de 2008 recebemos o Aluno A em nosso colégio. Me preocupei muito por falta de estrutura, até hoje não contamos com sala de recursos. Encarei o desafio, no primeiro bimestre foi muito difícil, nossa atenção estava toda voltada para ele, não tínhamos intérprete. A classe contava com trinta e quatro alunos, não rendeu como as demais quintas séries. A angústia aumentava a cada dia. Depois de muitas reuniões, inclusive com o Núcleo Regional de Educação e com a Escola Geny Ribas, o Colégio recebeu a intérprete. Eu sempre me comuniquei bem com ele, depois com a inserção da intérprete me senti mais livre para 
ministrar as aulas e pude dar mais atenção para o restante da classe que seguramente estavam prejudicados. Na minha disciplina no início do ano letivo, o aluno surdo apresentou dificuldades, pois agora já está na $5^{\mathrm{a}}$ série, enfrentou grandes mudanças, precisou de muita dedicação dele, da mãe e dos professores. O aluno é bom em Matemática, a única dificuldade é na interpretação de situações-problemas. No transcorrer do ano letivo, apresentou excelente crescimento e acredito que não apresentará grandes dificuldades no estudo da Matemática na $6^{a}$ série. (informação verbal).

\section{Declaração do professor de Geografia:}

O Aluno A foi a primeira experiência de praticar educação especial, em vinte anos de trabalho. $\mathrm{O}$ desafio era enorme, me gerou ansiedade e contentamento, porque eu me encontrava cursando o nível médio do Curso de Libras. Então desde o início, ocorreu aprendizagem mútua, eu exercia a Língua de Sinais e ele absorvia os conteúdos de Geografia. É um excelente copista, mas em decorrência da própria surdez, não escreve sozinho, a partir de um desenho ou sinal.

As avaliações eram sempre com mapas ou Atlas, e ele dominava o conteúdo às vezes muito melhor que outros alunos ouvintes da turma. Foi aprovado por média sem recuperação em nenhum bimestre. A partir de abril, chegou a intérprete no colégio depois de muita luta, insistência junto ao NRE (Núcleo Regional de Educação), o desespero marcante nos professores que não podiam dar aula para duas situações radicalmente diferentes, e simultaneamente sabiam que uma das partes estava saindo prejudicada.

A presença da intérprete inibiu um pouco o contato que tínhamos, desenvolvemos um vínculo de cumplicidade e relação de confiança. Em 2009, hoje $6^{a}$ série, optei por trabalhar com o aluno surdo novamente, continuarei a aprender com ele e ele o conteúdo, a única diferença que este ano é Historia a disciplina e não Geografia. Continuamos com o mesmo problema de 2008 inicialmente sem intérprete. (informação verbal). 


\section{Declaração do professor de História:}

No início do ano letivo de 2008, senti muita angústia em relação ao Aluno A, pois sem conhecimento de Libras ficou difícil a comunicação sem intérprete. No decorrer das aulas percebi que fazia leitura labial, então ficamos mais tranquilos, "nós dois”. Procurei trabalhar sempre me policiando para não lhe dar as costas, na hora de transmitir os conteúdos, e conseguimos nos relacionar bem, por ser um aluno muito esperto, acompanhou as aulas com êxito. A partir do segundo bimestre contamos com o trabalho da intérprete, que foi de grande valia, repassando a ele os conteúdos ministrados, enquanto a minha atenção se voltava agora com mais ênfase para toda a turma. É um aluno muito educado e carismático. Teve um excelente relacionamento com os colegas e professores. (informação verbal).

\section{Declaração do professor de Língua estrangeira - Inglês:}

Quando eu soube, através da direção, que haveria a inclusão de um aluno surdo na $5^{\mathrm{a}}$ série, senti-me apreensiva. Ninguém havia nos preparado para isso. Como eu faria para trabalhar Língua Estrangeira com um aluno surdo? Fiquei perdida. A convivência no dia-a-dia mostrou-se não muito fácil, apesar da relação professor/aluno ter sido muito boa. Ele é um aluno querido, afável, sociável e demonstrou ter vontade de aprender. As dificuldades de trabalhar Língua Estrangeira foram grandes. Muitas vezes ele tornava totalmente disperso, talvez por não estar entendendo o conteúdo. No final, creio que o saldo tenha sido positivo. Optei por trabalhar com ele em 2009, agora $6^{\text {a }}$ série e dar continuidade ao trabalhado iniciado, até mesmo porque já nos conhecemos, acredito que facilita, ao contrário com uma nova professora, esta iniciaria do zero, como eu. (informação verbal).

\section{Declaração do professor de Língua Portuguesa:}

O Aluno A é bastante esperto, ativo, caprichoso, simpático, de fácil relacionamento com a turma, sociável e bom copista. Porém, particularmente no trabalho com a Língua Portuguesa, eu, professora e o Aluno A não conseguimos nos comunicar bem durante o ano letivo de 2008. Não por falta de afetividade ou afinidades pessoais e boa vontade de ambos, mas pelo fato de que ele não decodifica palavras num contexto, 
mas isoladamente, pelo fato de muitas palavras de Língua Portuguesa não terem suas correspondentes em Libras (Língua de Sinais). Com a chegada da intérprete, já havia transcorrido o primeiro bimestre, houve grande melhora. No entanto, alguns conteúdos gramaticais como preposição, conjunções, artigos, flexão de substantivos e adjetivos, concordância verbal e nominal, entre outros, não dispõem de equivalência em Libras. Quanto à leitura, interpretação e possível produção de textos, trabalhos com resumos, tornaram-se e continuaram muito difíceis, comprometendo todo esse processo linguístico. (informação verbal).

\section{Declaração do professor de Treino de Futsal:}

O Aluno A enquanto atleta, não apresentou nenhuma dificuldade durante os treinos. Ele se mantinha muito atento em relação à bola, ao espaço físico e aos companheiros, sempre olhando para a professora, para ver se recebia alguma orientação. Os companheiros sabendo da surdez, sempre olhavam para ele facilitando a comunicação, utilizandose de gestos característicos da modalidade de futsal. Treinou por dois meses. A mãe não permitiu sua participação nos Jogos Municipais e ele nunca mais voltou a treinar. Às vezes a discriminação começa na própria família, por vergonha ou proteção. A atitude tomada entra em choque com o Regulamento dos Jogos Colegiais do Paraná: "Parágrafo quarto - os alunos com deficiência auditiva ou surdez participarão da competição na categoria regular de ensino. Caso a equipe possua alunos com deficiência auditiva ou surdez deve informar através da ficha de inscrição, em campo próprio.

Art. 30 - Os (as) professores (as) e intérpretes de Libras poderão acompanhar mediante identificação.” Essa informação na ficha de inscrição serve para avisar a arbitragem que deverá olhar para o atleta caso esse sofra alguma infração. (informação verbal).

\section{Conclusão}

A luta pelas modificações idealistas na educação são permanentes e constantes, expostas em legislação, decretos, movimentos sociais, ONG's, associações. A representatividade dos deficientes é extremamente restrita nas 
diferentes esferas da sociedade. O direito que por eles deveria ser exercido, e o espaço devidamente merecido e não reconhecido, são ignorados.

Quando se trata de educação inclusiva o texto da lei é claro, contundente, mas absurdamente incompleto ao ser colocado em prática, porque o texto é frio e calculista, não consegue detectar sentimentos, aprendizagens, limitações ou barreiras.

No que concerne aos deficientes auditivos, nem ao menos gritar eles podem, porque não ouvem e consequentemente não falam, afinal, essa fala só seria possível através de exercícios com as cordas vocais para copiar sons inaudíveis, processo lento, doloroso e que exige além de suas capacidades físicas.

Portanto postulamos que terá que existir sempre um ouvinte como intermediário para que a comunicação ocorra, salvo se ambos conhecerem a Língua de Sinais, ou existir a presença de um intérprete, quantitativamente inexpressivo em nossa região.

O estudo de caso comprovou a ineficiência, o fracasso interior, a angústia do profissional incapacitado para exercer sua atividade profissional no mundo real, “Tenho um aluno surdo. E agora?”. Questões similares a essa surgem constantemente na proposta de educação inclusiva. $\mathrm{O}$ aluno foi inserido no ensino regular sem estrutura profissional. A ausência de intérprete desde o inicio do ano letivo dificultou o aprendizado de muitas disciplinas.

Apenas uma professora (disciplina de Geografia) apresentava conhecimento sobre linguagem de sinais o que possibilitou-lhe um maior auxílio ao aluno na compreensão do conteúdo. As demais disciplinas eram ministradas através da utilização da linguagem oral (de domínio dos ouvintes) fazendo com que o aluno não tivesse possibilidade de se apropriar dos conhecimentos repassados.

Com base no estudo desse caso, percebemos as mazelas que estão enraizadas no processo de inclusão. Deve-se primeiro preparar intérpretes (linguagem, amplos conhecimentos, estrutura emocional e pedagógica), capacitar professores, mobilizar a equipe escolar, dirigentes locais, acompanhar e assessorar com diagnósticos temporários a validação da evolução da trajetória escolar. Compete ao Estado exigir formação continuada dos professores. 
Com essa articulação, que poderá ser reformulada ou aprimorada a qualquer tempo, poderia então se desmantelar a estrutura de educação especial e verdadeiramente inserir o educando no ensino regular, proporcionando a ele uma educação especial de qualidade, garantindo-lhe os mesmos direitos que um cidadão, tido como "normal”, tem na sociedade.

\section{Referências}

BRASIL. Plano Nacional de Educação. Diário Oficial da União. Brasileira, 10 jan. 2001.

BRASIL, Ministério da Educação, Secretaria de Educação Especial. Diretrizes nacionais para a educação especial na educação básica. Brasília: Mec/SEESP.

BRASIL, Ministério da Educação. Secretária de Educação Especial. Projeto escola viva: garantindo o acesso e permanência de todos os alunos na escola: alunos com necessidades educacionais especiais. Brasília, v. 1 a 6, 2000.

BRASIL, Ministério da Educação. Secretaria de educação fundamental. Parâmetros Curriculares Nacionais: adaptações curriculares; estratégias para educação de alunos com necessidades educacionais especiais. Brasília: MEC/SEF/SEESP, 1999.

BRASIL, Congresso Nacional. Constituição da República Federativa. 1988.

BRITO, L. F. Integração social e educação de surdos. Rio Janeiro: Editora Babel, 1993.

BUENO, J. G. S. Excepcionalidade, história e conceito: educação especial brasileira: integração/segregação do aluno diferente. São Paulo: EDUC, 1993, p.27-40.

DECLARAÇÃO DE SALAMANCA. UNESCO. Espanha, 1994.

FELIPE, T. A. Bilinguismo e surdez. In: CONGRESSO BRASILEIRO DE LINGÜÍSTICA APLICADA, 1. Anais... São Paulo: Universidade Estadual de Campinas, 1983.

FENEIS- Federação Nacional de Educação e Integração dos Surdos. Kit libras é legal ! Porto Alegre: FENEIS-RS, 2002.

FERNANDES, E. Problemas lingüísticos e cognitivos do surdo. Rio de Janeiro: Editora Agir, 1990.

FERREIRA, G. E. Língua e sinais, cooperar: psicologia e sociedade. Belo Horizonte, 2000.

GOLDFELD, M. A criança surda: linguagem e cognição numa perspectiva sócio-interacionista. São Paulo: Editora Plexus, 1997.

MAZZOTTI, T. B. Produção escolar. Caderno educativo. Jul-dez, 1989.

MONTOAN, M. T. E. Inclusão escolar: o que é? Por quê? Como fazer? São Paulo: Moderna, 2003.

RAMOS, C. R.; GOLDFELD, M. Vendo vozes: os passos dados na direção da realização de 
um programa de televisão para crianças surdas. Revista Geles, n.06, ano 5, Rio de Janeiro: Babel, 1992.

SACKS, O. Vendo vozes: uma jornada pelo mundo dos surdos. Rio Janeiro: Imago, 1989.

SKLIAR, C. (Org.). A surdez: um olhar sobre as diferenças. Porto Alegre: Mediação, 1998.

SASSAKI, R. Inclusão: construindo uma sociedade para todos. Rio de Janeiro: WVA, 1997.

WERNECK, H. Se você finge que ensina, eu finjo que aprendo. Petrópolis: Vozes, 1992.

BUENO, K. A aprendizagem dos surdos inclusos nas classes de ensino regular. 2006, 59. Universidade Estadual de Ponta Grossa, Ponta Grossa 2006.

KOJIMA, C.; SEGALA, C. LIBRAS - Linguagem Brasileira de Sinais: imagem do pensamento. São Paulo: Escala, v. 1, 2, 3, 2008.

ROSA, D. et al. Políticas organizativas e curriculares, educação inclusiva e formação de professores. Rio de Janeiro: DP\&A, 2002.

Recebido para publicação em 17 junho de 2009. Aceito para publicação em 09 novembro 2009. 